\title{
Small molecule modulation of splicing factor expression is associated with rescue from cellular senescence
}

\author{
Eva Latorre1, Vishal C. Birar², Angela N. Sheerin², J. Charles C. Jeynes ${ }^{3}$, Amy Hooper ${ }^{1}$, Helen R. Dawe ${ }^{4}$, \\ David Melzer ${ }^{1}$, Lynne S. Cox ${ }^{5}$, Richard G. A. Faragher ${ }^{2}$, Elizabeth L. Ostler ${ }^{2^{*}}$ and Lorna W. Harries ${ }^{1^{*}}$
}

\begin{abstract}
Background: Altered expression of mRNA splicing factors occurs with ageing in vivo and is thought to be an ageing mechanism. The accumulation of senescent cells also occurs in vivo with advancing age and causes much degenerative age-related pathology. However, the relationship between these two processes is opaque. Accordingly we developed a novel panel of small molecules based on resveratrol, previously suggested to alter mRNA splicing, to determine whether altered splicing factor expression had potential to influence features of replicative senescence.
\end{abstract}

Results: Treatment with resveralogues was associated with altered splicing factor expression and rescue of multiple features of senescence. This rescue was independent of cell cycle traverse and also independent of SIRT1, SASP modulation or senolysis. Under growth permissive conditions, cells demonstrating restored splicing factor expression also demonstrated increased telomere length, re-entered cell cycle and resumed proliferation. These phenomena were also influenced by ERK antagonists and agonists.

Conclusions: This is the first demonstration that moderation of splicing factor levels is associated with reversal of cellular senescence in human primary fibroblasts. Small molecule modulators of such targets may therefore represent promising novel anti-degenerative therapies.

Keywords: Alternative splicing, Ageing, Resveratrol, Senescence, Fibroblasts

\section{Background}

Messenger RNA (mRNA) processing has been implicated as a key determinant of lifespan. Splicing factor expression is dysregulated in the peripheral blood of aging humans, where they are the major functional gene ontology class whose transcript patterns alter with advancing age [1] and in senescent primary human cells of multiple lineages [2]. Splicing factor expression is also an early determinant of longevity in mouse and man [3], and in both species these changes are likely to be functional, since they are associated

\footnotetext{
* Correspondence: E.Ostler@brighton.ac.uk; L.W.Harries@exeter.ac.uk Eva Latorre and Vishal C. Birar are co-first authors.

Richard G. A. Faragher, Elizabeth L. Ostler and Lorna W. Harries are co-senior authors.

${ }^{2}$ School of Pharmacy and Biomolecular Sciences, University of Brighton, Cockcroft Building, Moulsecoomb, Brighton BN2 4GJ, UK

${ }^{1}$ Institute of Biomedical and Clinical Sciences, University of Exeter Medical School, University of Exeter, Barrack Road, Exeter, Devon EX2 5DW, UK Full list of author information is available at the end of the article
}

with alterations in splice site usage for many genes [1-3]. Recent data suggests that modification of the levels of SFA1 , a core component of the spliceosome, influences lifespan in C. elegans through interaction with TORC1 machinery [4]. Diseases for which age is a significant risk factor including Alzheimer's disease [5], Parkinson's disease [6] and cancer [7] are also marked by major changes in the isoform repertoires, highlighting the importance of correct splicing for health throughout the life course. Thus, the loss of finetuning of gene expression in ageing tissues and the resulting failure to respond appropriately to intrinsic and extrinsic cellular stressors has the potential to be a major contributor to the increased physiological frailty seen in aging organisms [8].

The splicing process is regulated on two levels. Firstly, constitutive splicing is carried out by the core spliceosome, which recognises splice donor and acceptor sites that define 
introns and exons. However, fine control of splice site usage is orchestrated by a complex interplay between splicing regulator proteins such as the Serine Arginine (SR) class of splicing activators and the heterogeneous ribonucleoprotein (hnRNP) class of splicing repressors. Splicing activators bind to exon and intron splicing enhancers (ESE, ISE), and splicing inhibitors to intron and exon splicing silencers (ESS, ISS). Splice site usage relies on the balance between these factors and occurs in a concentration-dependent manner [9-11]. Other aspects of information transfer from DNA to protein, such as RNA export and mRNA stability are also influenced by splicing factors [12]. Intriguingly, in addition to their splicing roles, many splicing factors have non-canonical additional functions regulating processes relevant to ageing. For example, hnRNPK, hnRNPD and hnRNPA1 have been shown to have roles in telomere maintenance [13-15], hnRNPA1 regulates the stability of SIRT1 mRNA transcripts [16] and hnRNPA2/B1 is involved in maintenance of stem cell populations [17]. Splicing factor expression is known to be dysregulated in senescent cells of multiple lineages [2] and it is now well established that the accumulation of senescent cells is a direct cause of multiple aspects of both ageing and age-related disease in mammals [18].

Senescent cells accumulate progressively through life in a variety of mammalian species [15], and premature senescence is a hallmark of many human progeroid syndromes. Conversely, dietary restriction, which increases longevity, retards the accumulation of senescent cells. Most compellingly, deletion of senescent cells in transgenic mice improves multiple aspects of later life health and extends lifespan [19]. The mechanisms by which senescent cells mediate these deleterious effects are complex but include factors such as ectopic calcification in the case of vascular smooth muscle cells [20] and secretion of pro-inflammatory cytokines, the well-known Senescence Associated Secretory Phenotype (SASP) [21]. These observations suggest that an interrelationship may exist between well characterised mechanisms of ageing, such as cellular senescence, and the RNA splicing machinery where the mechanistic relationship to ageing remains largely correlational.

In contrast to the situation with core spliceosomal proteins such as SFA-1, perturbation of a single splicing regulator by standard molecular techniques such as knockdown or overexpression is unlikely to be informative for assessment of effects on ageing and cell senescence, since ageing is characterised by co-ordinate dysregulation of large modules of splicing factors $[1,2]$. Splice site choice is also dependent on the balance between more than a hundred splicing activator and splicing inhibitor regulatory proteins, which differ from splice site to splice site and from tissue to tissue $[9,10]$. Thus experimental tools capable of coordinately modulating the expression of multiple components simultaneously are required to address the potential effects of the dysregulation of large numbers of splicing factors that we note during the ageing process. Small molecules such as resveratrol have been reported to influence splicing regulatory factor expression in transformed cell lines such as HEK293 and HeLa [22], although it is not yet known whether this is a direct or indirect effect. Unfortunately, resveratrol has multiple biological effects, including a reduction of pro-inflammatory cytokine expression [23] as well as its canonical activity against SIRT1 [24] thus a 'clean' assessment of the effects of moderation of splicing factor levels on cell physiology cannot be achieved using this compound alone.

We have overcome this limitation through development of a novel library of resveratrol-related compounds (resveralogues) which are all capable of either directly or indirectly influencing the expression of multiple splicing factors of both SRSF and HNRNP subtypes, whilst exhibiting differential activity against SIRT1 and SASP. Treatment of senescent human fibroblasts from different developmental lineages with any of these novel molecules shifts expression patterns of multiple splicing factors to those characteristic of much earlier passage cells. This change occurs regardless of cell cycle traverse and is associated with a marked decrease in key biochemical and molecular biomarkers of senescence without any significant alteration in levels of apoptosis. Elevated splicing factor expression is also associated with elongation of telomeres, and in growth permissive conditions, these previously senescent populations show significant increases in growth fraction (as measured by Ki67 staining) and in absolute cell number, indicating cell cycle reentry. The mechanisms by which 'rejuvenation' occurs are independent both of SIRT1 activation, or effects on the SASP. Thus, molecules that modulate RNA splicing patterns, either directly or indirectly, may have the potential to delay or reverse cellular senescence with consequent positive impact on human health span.

\section{Results}

\section{Synthesis of novel resveralogues}

Resveratrol (RSV) has been reported to extend lifespan in various model organisms through activation of the NAD-dependent protein deacetylase, SIRT1 [24], while replenishment of $\mathrm{NAD}^{+}$improves lifespan and health span in $\mathrm{ATM}^{-}$worms and mice [25]. We therefore set out to rationally design a panel of novel resveratrol-like compounds (Fig. 1a) with the goal of identifying compounds that could restore splicing factor expression to levels comparable with those seen in young cells, but with differing effects on SIRT1 activation and the senescence-associated secretory phenotype (SASP) to allow assessment of molecular mechanism. Synthesis of the backbone was achieved as previously reported [26], with additional functionality and diversity achieved via 
a<smiles>Oc1ccc(C=Cc2cc(O)cc(O)c2)cc1</smiles><smiles>COc1cc(/C=C/c2ccc(NS(C)(=O)=O)cc2)cc(OC)c1</smiles><smiles>COc1cc(/C=C/c2ccc(-c3nnn[nH]3)cc2)cc(/C=C/c2ccccc2-c2nnn[nH]2)c1</smiles>

b<smiles>CC(=O)Nc1ccc(/C=C/c2cc(O)cc(O)c2)cc1</smiles>

i

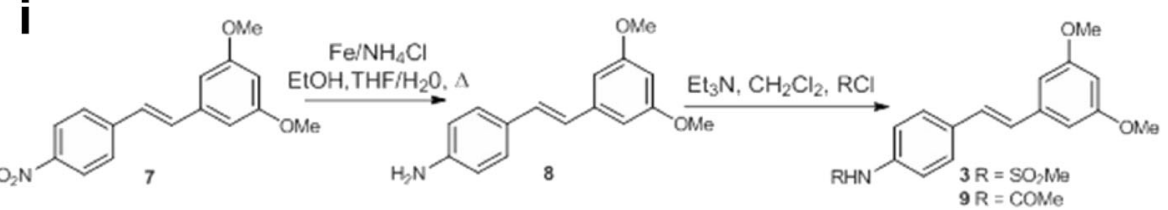

ii<smiles>COc1cc(/C=C/c2ccc(NC(C)=O)cc2)cc(OCCCOC(C)=O)c1</smiles>

II
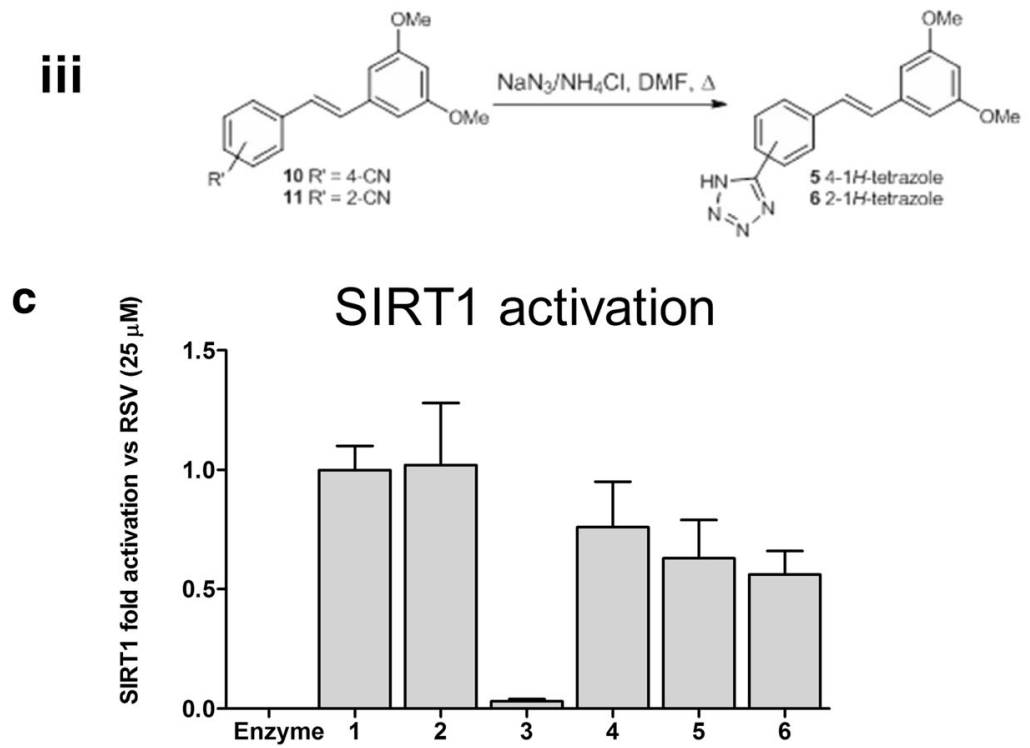

Fig. 1 Synthesis and characterisation of novel resveralogues. a Structures of resveralogues 1-6. Compounds are: $\mathbf{1}$ resveratrol, 2 resveratrol's primary metabolite, dihydroresveratrol, 3 (E)-N-(4-(3,5-dimethoxystyryl) phenyl)methanesulfonamide, 4 (E)-N-(4-(3,5-dihydroxystyryl)phenyl)acetamide, 5 (E)-5-(4(3,5-dimethoxystyryl)phenyl)-1 H-tetrazole and $\mathbf{6}$ (E)-5-(2-(3,5-dimethoxystyryl)phenyl)-1 H-tetrazole. b Scheme of synthesis of compounds 3-6 (see Methods for details). c Fluorescence determination of SIRT1 activity in vitro in the presence of $25 \mu \mathrm{M}$ each compound, normalised against resveratrol (1) and vehicle only control (0). Data are presented as fold change (mean \pm SD) in activity normalised to enzyme-only (0) and resveratrol (1), such that 0 represents no activation, and 1.0 indicates activation equivalent to that observed with resveratrol 1 . The experiment was carried out in 3 replicates. The numbers on the $X$ axis (1-6) refer to the identity of each resveralogue as indicated above. Uncertainty was calculated by subjecting the standard deviation of the control, Resveratrol and compound data to combination using standard methods for propagation of uncertainty [49]

functional group interconversion (Fig. 1b). Compounds were chosen for further analysis based on (i) structural novelty and low cytotoxicity (ii) differential SIRT1 activation activity (iii) differential effects on the suppression of SASP components and (iv) previously observed increases in the Ki67 positive fraction of MRC5 cultures at $5 \mu \mathrm{M}$. We also included the parent compound (resveratrol) and a major metabolite (dihydroresveratrol). 
SIRT1 activation is significantly altered following side chain modification of resveratrol

Since RSV has been suggested to exert its pro-longevity effects predominantly through activation of SIRT1, we first tested the ability of our novel compounds to activate SIRT1 in an ex vivo enzyme assay (Fig. 1c), with data normalised against activity detected on treatment with resveratrol (RSV, 1). While dihydroresveratrol (Fig. 1a, 2) displayed SIRT1-activation activity equivalent to that of resveratrol, the four novel analogues (3-6) displayed a range of activities from zero (compound 3) to around $75 \%$ of control levels (compound 4) (Fig. 1c). These marked differences in SIRT1 activation by the novel resveralogues (compared with RSV and DHRSV) therefore allow us to probe SIRT1dependence of any biological effects.

\section{Impact of resveralogues on the senescence-associated secretory phenotype}

We then set out to determine if treatment with resveratrol or the novel resveralogues had an impact on the senescence-associated secretory phenotype (SASP) in senescent cultures of human fibroblasts (NHDF). The levels of multiple cytokines including key SASP components (IL6, IL8, TNF $\alpha$, IL2, IL1 $\beta$, IL-12p70, IL10, INF $\gamma$ and GMCSF) were determined in senescent NHDF by ELISA (Fig. 2). Although each of the compounds altered cytokine profiles to some extent (Fig. 2, see also Additional file 1: Table S1), there was no consistent pattern with which this occurred. Resveratrol $\mathbf{1}$ was the only compound to reduce

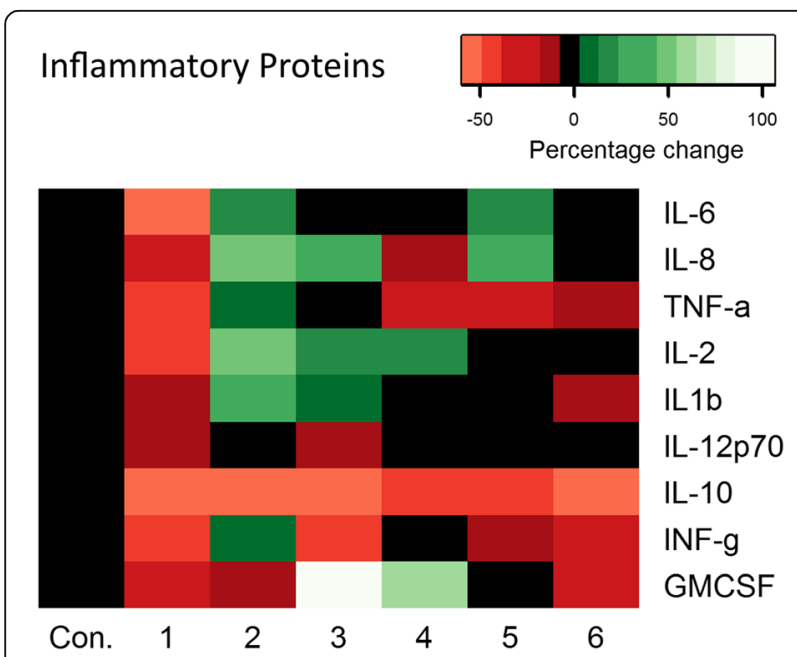

Fig. 2 Differential effects of resveralogues on the senescenceassociated secretory phenotype (SASP). Protein levels of various pro-inflammatory SASP factors was determined using Mesoscale ELISA platform in culture medium of senescent HNDF cultures treated with $5 \mu \mathrm{M}$ resveralogues 1-6. The heat map indicates fold changes. Con = control (vehicle only). Green indicates up-regulation while red denotes down-regulation. The colour scale refers to percentage change in expression. Experiments were carried out in duplicate a total of 10 times the levels of multiple cytokines including the key SASP mediators IL-6 and IL- 8 as well as IL2, TNF $\alpha$ and IFN $\gamma$, consistent with previous reports [27]. By contrast, dihydroresveratrol (2) treatment significantly elevated levels of IL-8 and several other inflammatory mediators, whilst 36 had variable impact on the expression of the SASP proteins assayed. The only cytokine showing a consistent reduction in level in response to all 6 compounds was IL10 (Fig. 2, Additional file 1: Table S1).

\section{Splicing factor expression and splicing patterns of senescence-associated genes are restored in senescent cultures of fibroblasts following treatment with resveralogues}

To establish whether RSV and the novel resveralogues could influence splicing regulators, we first measured splicing factor expression by qRT-PCR in senescent cultures of human fibroblasts (NHDF) following $24 \mathrm{~h}$ treatment with $5 \mu \mathrm{M}$ of compounds 1-6. Consistent with previous studies in HEK293 cells [22], we find that resveratrol (1) treatment increased levels of both splicing activators (SRSF transcripts) and inhibitors (HNRNP transcripts) (Fig. 3a). Importantly, novel resveratrol analogues also partially restored levels of both splicing activator and inhibitor transcripts (Fig. 3a, Additional file 2: Table S2). The level of restoration of splicing regulator expression in treated cells was similar to levels previously reported in early passage fibroblasts [2]. This reversal of the age-related decline in splicing factor expression was present for compounds with no discernible SIRT activity (compound 3) as well as those that elevated IL6 and IL8 levels (compounds 2 and 5), indicating that the action of splicing factors is independent of SIRT1 and the SASP.

We then asked whether this restoration of a 'youthful' complement of splicing factors is biologically relevant. To do this, we examined the alternative splicing profiles of key genes involved in cellular senescence in senescent NHDF cultures treated with each of the compounds (Fig. 3b). In some cases, it was not possible to distinguish an effect on splicing from effects on transcription, since multiple isoforms were affected with the same directionality. For example, both $p 14 A R F$ and $p 16 I N K 4 A$ isoforms of the $C D K N 2 A$ gene, which increases with cellular senescence [28], were down-regulated in response to treatment with most resveralogues. However, in other cases, only one isoform was affected; the expression of the proapoptotic p21b isoform, but not the consensus isoform p21a of the CDKN1A gene was altered, demonstrating an effect on splicing. Similarly, increased expression of the CHK1S isoform of the CHK1 gene, which induces mitosis [29], but not the consensus CHK1 isoform which does not, was seen (Additional file 2: Table S2). SIRT1 mRNA expression was upregulated by treatment with the novel 
a

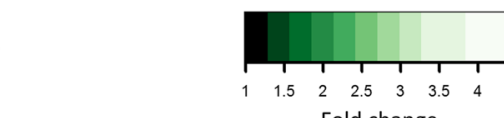

Fold change

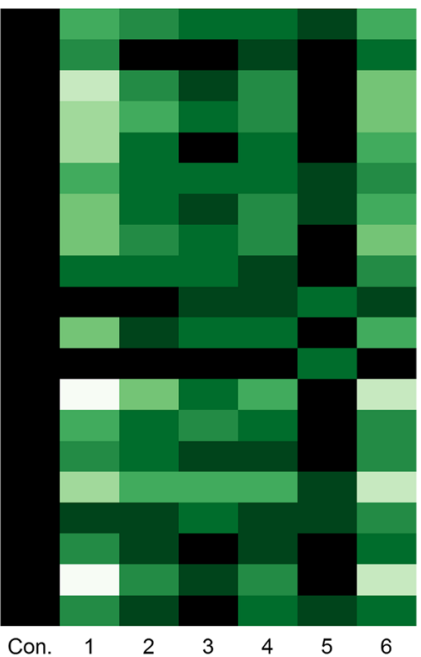

b

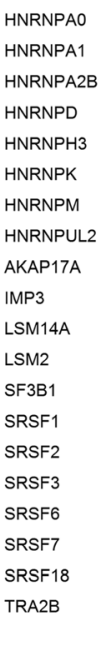

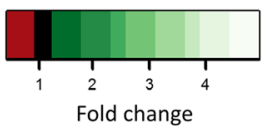

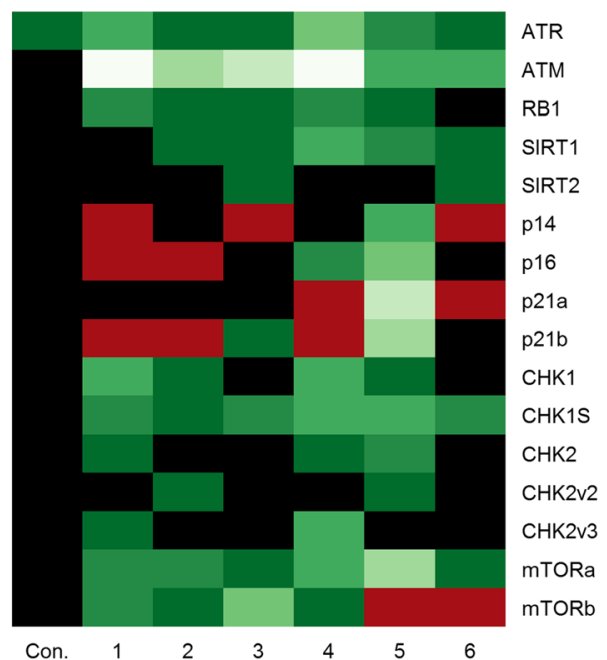

Fig. 3 Splicing factor regulators are elevated following treatment with resveratrol analogues. Changes to mRNA levels in HNDF cells in response to treatment with $5 \mu \mathrm{M}$ resveratrol (1) or resveralogues 2-6 determined by quantitative reverse transcription PCR. a Expression of splicing factor regulatory genes $(\mathbf{b})$ Isoform-specific transcripts of genes associated with senescence and/or DNA damage responses. Con $=$ control (vehicle only). Green indicates up-regulated genes, red denotes down-regulated genes. The colour scale refers to fold-change in expression. Data are derived from duplicate testing of 3 biological replicates

resveralogues but not RSV itself. A major regulator of cell proliferation and potential driver of senescence is mTOR: inhibition of mTORC1 by rapamycin increases longevity in animal models [30], while mTORC inhibition can reverse multiple phenotypes of cell senescence [31]. We found elevated expression of both the mTOR $\alpha$ and $\beta$ isoforms, which regulate cell metabolism and cell proliferation respectively [32], on treatment with resveralogues 14 (Fig. 3b, Additional file 2: Table S2), though mTOR $\beta$ was suppressed on exposure of cells to resveralogues 5 and 6. Overall, the changes in alternatively-expressed isoforms following resveralogue treatment are consistent with a shift towards a more proliferation-competent repertoire.

\section{Treatment of senescent cells with resveralogues is} associated with reduction in biomarkers of senescence To assess whether restored splicing factor expression was associated with rescue from cellular senescence, we treated senescent cultures of normal human diploid fibroblasts from three genetically distinct cell strains (NHDF and HF043 dermal fibroblasts and MRC5 lung fibroblasts) for $24 \mathrm{~h}$ with compounds 3-6, compared with RSV (1) and DHRSV (2) and measured transcript levels of senescence biomarkers CD248 and CDKN2A (encoding $\mathrm{p} 16^{\mathrm{INK} 4 / 6}$ ) by quantitative reverse transcription PCR, normalised against the IDH3B, GUSB and PPIA endogenous control genes, which we have found to be stable in response to senescence and ageing in our previous work $[1,2]$. Stability of control genes to resveralogue treatment was verified empirically. While we observed differences between the cell lineages, there was an overall significant decrease in CDKN2A and CD248 molecular markers of senescence compared with vehicle-only control cell populations (Fig. 4a), which was most marked for the foreskin fibroblast line HF043. To further assess senescence, we examined levels of senescence-associated $\beta$ galactosidase (SA $\beta$-Gal). The percentage of NHDF cells staining positive for SA $\beta$-Gal decreased from $\sim 75$ to $\sim 25 \%$, compared with much lower levels $(\sim 7 \%)$ in younger cells at PD25 (Fig. 4b), and similar highly significant reductions in SA $\beta$-Gal reactivity were seen in senescent cultures of MRC5 and HF043 fibroblasts (Fig. 4b). These reductions in senescence markers were still evident in NHDF cells 4 weeks after initial treatment and larger reductions occurred following repeated treatments at $48 \mathrm{~h}$ intervals (Additional file 3: Figure S1). We conclude therefore that senescence markers are markedly diminished upon resveralogue treatment. Given that compound $\mathbf{3}$ (which does not activate SIRT1) has very similar effects on these senescence biomarkers compared with resveratrol and other resveralogues with variable SIRT-activation activity $(4,5,6)$, we can conclude that the decrease in senescence biomarker expression on resveralogue treatment can occur independently of SIRT1 activation. 


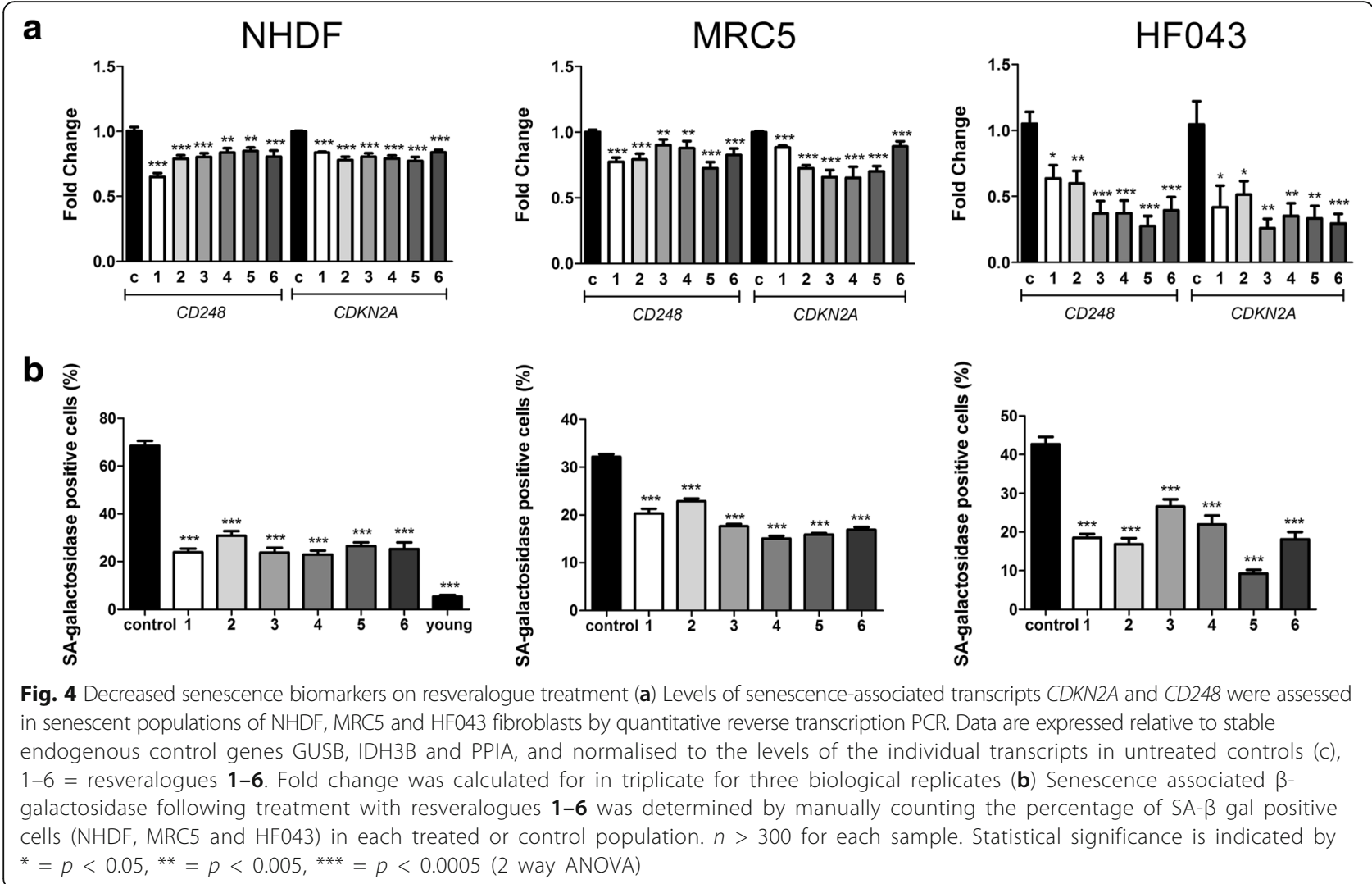

Treatment of senescent cells with resveralogues is associated with re-entry of cell cycle

While decreases in senescence biomarkers may be beneficial in alleviating some of the detrimental effects of senescent cells, it is the loss of proliferative capacity of senescent cell populations that is likely to lead to stem cell exhaustion and loss of tissue function/frailty with increasing age [33]. We therefore also assessed cell proliferation and re-entry into the proliferative cell cycle. Initially, using live cell imaging of senescent NHDF cells treated with resveratrol for up to $92 \mathrm{~h}$, we found that some cells within this population showed clear evidence of mitosis within a little as $17.5 \mathrm{~h}$ after treatment (Additional file 4: Figure S2). We therefore assessed whether senescent populations of three different fibroblasts lines (NHDF, MRC5 and HF043) could undergo mitosis following treatment with the novel compounds. Remarkably, treatment with even very low doses $(5 \mu \mathrm{M})$ of the resveralogues led to significant increases (up to 0.6 population doublings) in total cell numbers over only $24 \mathrm{~h}$ of drug exposure, while vehicle-only controls remained proliferation-arrested (Fig. 5a). Increases in cell number strongly suggest that a significant proportion of cells in the non-cycling senescent population have been induced to re-enter the mitotic cell cycle.
Cell proliferation kinetics are altered in treated cells To further probe this potential induction of proliferation, the proliferation kinetics of these cultures were determined by immunocytochemical and catalytic histochemical measurement of the levels of the proliferation marker, Ki67, and the senescence marker, SA $\beta-G a l$, respectively. Compounds 1-6 induced a consistent increase in the Ki67 positive fraction of cells in senescent NHDF cultures from $\sim 20 \%$ of nuclei to $\sim 40 \%$, whereas levels in younger cells at PD25 were $>90 \%$ (Fig. 5b), consistent with the findings of increased cell numbers and mitotic figures following drug administration (Fig. 5a, Additional file 4: Figure S2 and data not shown). Since the increased number of cells staining for the proliferation marker Ki67 correlates inversely with the decreased numbers staining for SA- $\beta$ gal (see Fig. $4 \mathrm{~b}$ ), we suggest that cells have exited senescence to enter the cell cycle.

\section{Treatment of senescent cells with resveralogues is associated with telomere elongation}

Telomere shortening is perhaps the best known trigger of cellular senescence. Several splicing factors have been previously demonstrated to unwind telomeres and activate telomerase and could thus potentially lengthen telomeres $[13,14,34]$. We therefore measured telomere length by qPCR in NHDF cells treated with $5 \mu \mathrm{M}$ 

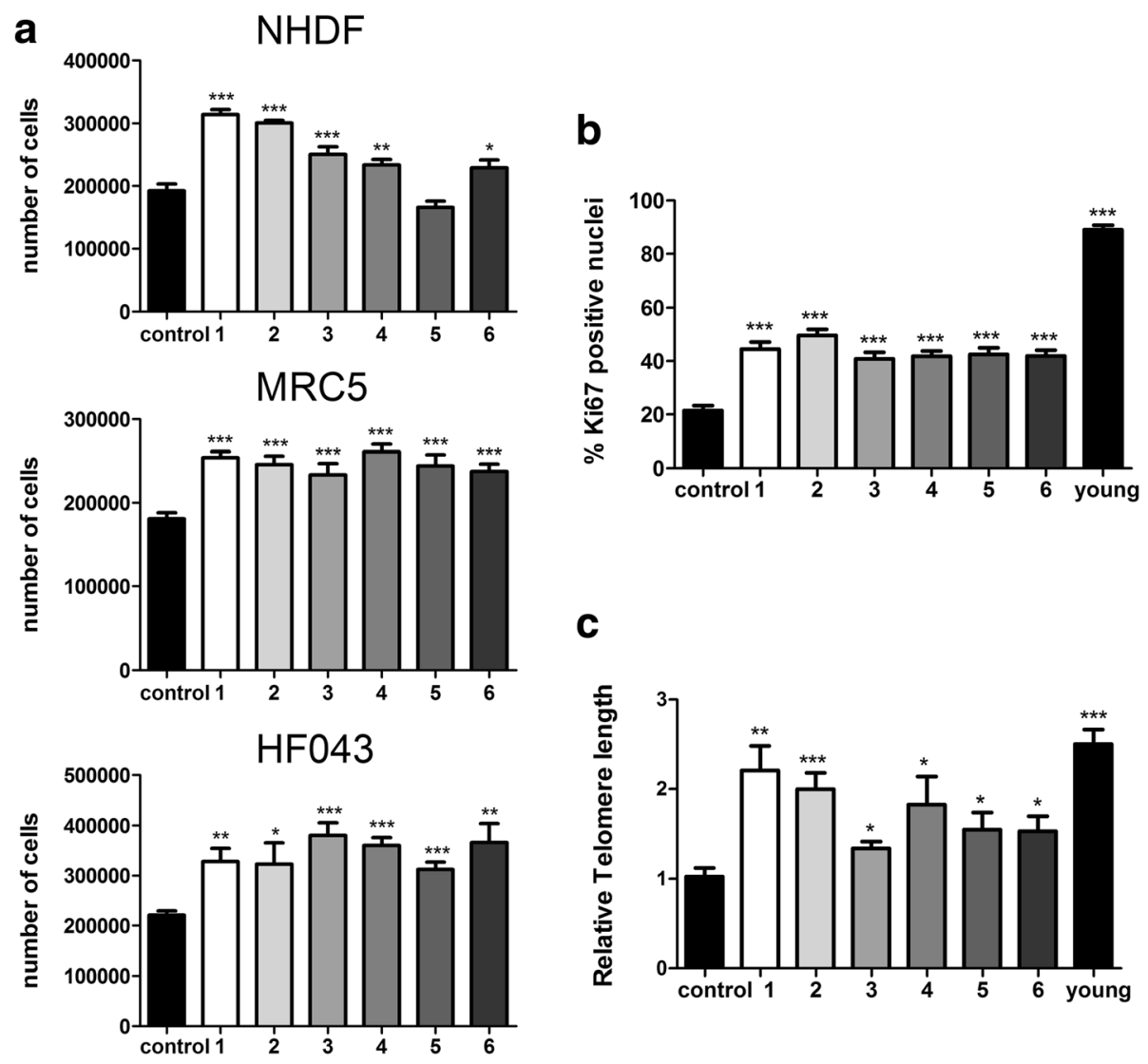

Fig. 5 Increased proliferation of senescent cell populations following resveralogue treatment. a Cell numbers of NHDF, MRC5 and HF043 fibroblast populations following treatment with resveralogues 1-6. Experiments were carried out in triplicate for three biological replicates and *** represents $p<0.001$ ( 2 way ANOVA). b Proliferation index was assessed for control and treated NHDFs, as well as younger (PD25) cells as assessed by Ki67 immunofluorescence ( $>400$ nuclei counted per sample, ${ }^{* * *} p<0.001$ by 2 way ANOVA). c Telomere length was quantified by qPCR relative to the $36 B 4$ endogenous control and normalised to telomere length in vehicle-only controls, younger passage cells (PD25) and in cells treated with compounds $\mathbf{1 - 6}$. Experiments were carried out in triplicate for three biological replicates. Statistical significance is indicated by ${ }^{*}=p<0.05,{ }^{* *}=p<0.005,{ }^{* *}=p<0.0005$ (2 way ANOVA)

resveratrol or resveralogues for $24 \mathrm{~h}$, relative to telomere length in untreated cells. We found that cells treated with resveratrol or any of the novel resveralogues had telomeres that were 1.3-2.4 times longer than vehicleonly controls, compared with younger cells at PD25, which showed telomeres 2.6 times longer than untreated senescent cells (Fig. 5c).

\section{Changes in splicing factor expression and senescence markers are not effects of cell proliferation}

To determine whether the changes in splicing factor expression were a cause or consequence of renewed cell proliferation, we measured splicing factor expression and selected senescence markers under low serum conditions, which would induce proliferating cells to enter quiescence. Unsurprisingly, serum-starved cultures demonstrated no increase in cellular proliferation in response to resveralogue treatment, as determined by lack of an observable increase in cell numbers (Fig. 6a) or
Ki67 index (Fig. 6b) in treated cells. However effects on both senescence markers (Fig. 6c) and splicing factor expression (Fig. 6d) were still observed, indicating that the effects on senescence and splicing factor expression were independent of proliferation. Uncoupling rescue from proliferation also allows us to quantify more precisely the percentage of cells in which senescence has been reversed from the dilution effect of increased cell number. The number of 'reverted' cells is $\sim 15 \%$, which is similar to the levels we had predicted based on the cell proliferation kinetics.

\section{Decrease in senescent cell fraction is not due to selective} death of senescent cells

To exclude the possibility that the decrease in the percentage of senescent cells following treatment resulted from selective cell death of non-proliferating cells, cytotoxicity was assessed using an assay for extracellular lactate dehydrogenase (LDH); this intracellular enzyme is 


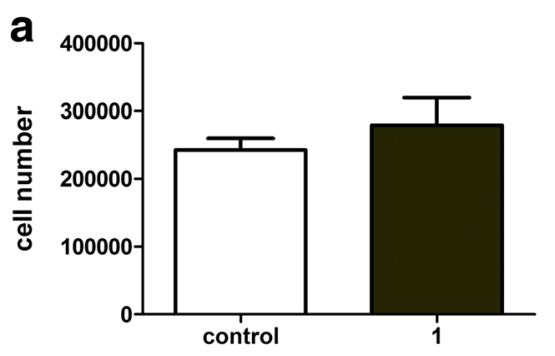

b
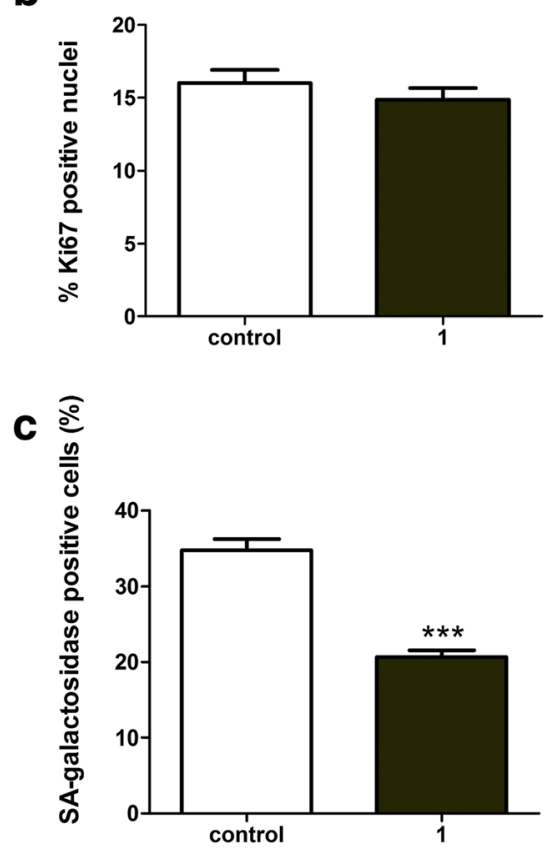

d
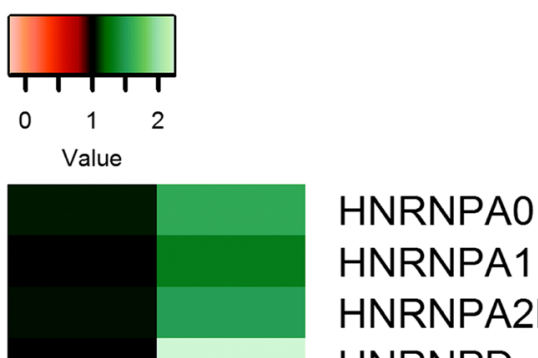

HNRNPA2B1

HNRNPD

HNRNPH3

HNRNPK

HNRNPM

HNRNPUL2

AKAP17A

IMP3

LSM14A

LSM2

SF3B1

SRSF1

SRSF2

SRSF3

SRSF6

SRSF7

SRSF18

TRA2B

Fig. 6 Effects of resveratrol treatment in cells grown under serum starvation conditions. a Cell numbers of NHDF fibroblasts following treatment with $5 \mu \mathrm{M}$ resveratrol for $24 \mathrm{~h}$ under conditions of serum starvation. Experiments were carried out in triplicate for three biological replicates. (2 way ANOVA). b Proliferation index was assessed for NHDF fibroblasts following treatment with $5 \mu \mathrm{M}$ resveratrol for $24 \mathrm{~h}$ under conditions of serum starvation as assessed by Ki67 immunofluorescence (> 400 nuclei counted per sample). c Senescence associated $\beta$-galactosidase following NHDF fibroblasts following treatment with $5 \mathrm{mM}$ resveratrol for $24 \mathrm{~h}$ under conditions of serum starvation was determined by manually counting the percentage of SA- $\beta$ gal positive cells in each treated or control population. $n>300$ for each sample. Statistical significance is indicated by $*^{* *}=p<0.0005$ ( 2 way ANOVA). $\mathbf{d}$ Changes to splicing factor mRNA levels in NHDF fibroblasts following treatment with $5 \mu \mathrm{M}$ resveratrol for $24 \mathrm{~h}$ under conditions of serum starvation determined by qRTPCR. Control = vehicle only. Green indicates up-regulated genes, red denotes down-regulated genes. The colour scale refers to fold-change in expression. Data are derived from duplicate testing of 3 biological replicates

only released into the culture medium upon cell death. In all cases, cells treated with the novel compounds released lower levels of LDH than those treated with RSV (at doses up to $100 \mu \mathrm{M}$ ) in comparison with vehicle only controls (Additional file 5: Figure S3); compound $\mathbf{6}$ in particular showed very low levels of LDH release. These results demonstrate low cytotoxicity of dihydroresveratrol and all four novel resveralogues.

While necrotic cell death was not detected, it was important to rule out selective loss of senescent cells by apoptosis. Levels of apoptosis in senescent NHDF cultures treated with resveralogues 1-6 were determined by both TUNEL and by Caspase 3 and 7 assays (Additional file 5 :
Figure S3B and C). No increases in levels of apoptosis were observed in the resveralogue-treated cultures compared with vehicle-only control treatments, suggesting that the increased proliferation on resveralogue treatment was not a consequence of selective death of nonproliferating cells within the population.

\section{ERK agonists and antagonists influence cellular senescence and splicing factor expression}

ERK signalling has previously been reported to be influenced by resveratrol $[35,36]$. ETS-1, a transcription factor downstream of ERK activation has also been reported to regulate the expression of $T R A 2 B$, an important splicing 
regulator [37]. To investigate the potential interplay between resveratrol and ERK signalling on splicing factor expression and cellular senescence phenotypes, we treated senescent NHDF cells with low dose $(1 \mu \mathrm{M}$ or $10 \mu \mathrm{M})$ of trametinib, a well-characterised signalling inhibitor that inhibits the ERK signalling pathway. Treatment of senescent cells with trametinib resulted in a robust decrease in the proportion of senescent cells in the culture, which was apparent at $1 \mu \mathrm{M}$ and $10 \mu \mathrm{M}$, but not at $20 \mu \mathrm{M}$. Such dose effects are not uncommon in signalling pathways due to interconnectivity with other signalling pathways and autoregulation (Additional file 6: Figure S4A). Conversely, treatment with the ERK agonist ceramide resulted in a comparable increase in the senescent cell fraction after $24 \mathrm{~h}$. Notably, the effect of ceramide was negated by the addition of $5 \mu \mathrm{M}$ of any of the novel resveralogues (Additional file 6: Figure S4B). Trametinib also restored splicing factor expression to profiles consistent with earlier passage in a manner similar to that observed with the resveralogues (Additional file 7: Figure S5).

\section{Discussion}

We have generated a panel of novel molecules based on the small molecule resveratrol, to determine whether alteration to regulators of mRNA processing could influence cellular senescence phenotypes in human fibroblasts of different lineages. Treatment of senescent cultures of cells from different genetic backgrounds with these novel molecules was associated with an increase in the expression of multiple splicing factors, to levels consistent with those seen in early passage cells [2], although at present it is not clear whether these are direct or indirect effects. Treatment with all 6 resveralogues also resulted in a decline in the senescent cell fraction, along with changes to the splicing patterns of genes involved in cell senescence to a profile indicative of much 'younger' cells. Our evidence suggests cells have also re-entered the cell cycle, as determined by an increase in markers of cell division with concurrent increases in cell number. Finally, in accordance with the reported role of some splicing factors on telomere accessibility and telomerase activity [13-15], telomere length was lengthened in treated cells, consistent with a 'resetting' of the telomere clock. The absence of any elevation of either necrotic (LDH release) or apoptotic cell death (TUNEL and caspase), also excludes the possibility that the dramatic decline in the senescent fraction results from selective killing of senescent cells by resveralogues.

Disruption to splicing factor transcript expression levels is known to be a major feature of ageing in humans [1] and also in senescent human primary cell lines of multiple lineages which have undergone in 'ageing' by repeated culture in vitro [2]. Splicing factor expression is also associated with lifespan in humans and also in mice, where their expression appears to be early-life determinants of longevity [3].
Recent data adds weight to this hypothesis, since abolition of the core splicing factor 1 (SFA-1) alone was to reduce lifespan in C.elegans by interaction with the TORC1 pathway [4]. Splicing factors are also known to be drivers of cell proliferation [38-40], through effects both on splicing patterns, and through their non-canonical roles in telomere maintenance [13-15, 17, 34]. Telomere maintenance is critical in permitting cell proliferation; restoration of hTERT allows prematurely senescing human Werner syndrome fibroblasts to proliferate with kinetics of wild type cells [41]. Splicing factors hnRNPK and hnRNPD interact with the hTERT promoter while knockdown of hnRNPD notably reduces transcription of the telomerase gene [13, 14]. Additionally, hnRNPA1 is required for telomere maintenance in multiple species and has been proposed to facilitate the access of telomerase to the telomere [15].

The question of whether senescence drives splicing changes, or whether splicing alterations are causative of cell senescence in different species, tissues and points in the life course is a challenging and multifaceted one. The conventional approaches to answer this question are intractable in this system, since there are over 100 splicing factors involved in regulation of splicing, with exon usage determined by the balance of activators and inhibitors at each individual splice site [10]. The pattern and dosage of splicing factors involved will also differ from splice site to splice site and from tissue to tissue. There is also redundancy between splicing factors, both in terms of regulation of splicing, and also in their non-canonical roles - at least $6 \mathrm{hnRNPs}$ and some SRSF proteins are known to have effects on telomere structure or telomerase activity. However, in this initial study the issue of causality can be distilled down to whether the changes in splicing factor expression we observe on resveralogue treatment drive rescue from senescence or are a consequence of re-entry into cell cycle. The observation that the alteration in splicing factor expression and the decrease in numbers of senescent cells occurs when proliferation is blocked provides evidence to suggest effects we note may lie upstream in the causal pathway (Fig. 5).

Presently, it is not possible to attribute specific splicing changes to alterations in the levels of specific splicing factors. Splice site choice is governed by the balance of activators and inhibitors at individual splice sites, and the binding sites are short and degenerate [10]. Similarly, in some cases, it is not possible to determine whether the effects on expression we note are transcriptional or due to splicing on the basis that expression changes of alternative isoforms share directionality. However, for other genes, the effect is confined to specific isoforms, clearly indicating an effect on splice site choice. Another caveat to our work is that we have assessed expression changes at the level of mRNA only. This is due to the inherent 
difficulty in culturing sufficient quantities of senescent cells to allow large scale protein analysis.

At present, the specific mechanism(s) by which resveralogues may influence splicing factor expression and senescence phenotypes in our work are not clear. Resveratrol has previously been demonstrated to have beneficial effects on senescence phenotypes through other pathways such as SIRT1 activity [24] and also through effects on the senescence-associated secretory phenotype (SASP) [23]. Our data suggest that resveralogues can influence splicing factor expression and cell division in senescent cultures independently of SIRT1 activity, since one compound, molecule 3 has no discernible SIRT1 activity (Fig. 1), despite an induction of SIRT1 at the mRNA level. The action of resveratrol on SIRT1 is at the level of enzyme activation. In the case of compound 3, although there appears to be an effect on transcription, this compound is not able to activate the translated protein. Our data are also consistent with earlier studies in siRNA SIRT1 knockout cells which demonstrated that the effect of resveratrol on splicing factor expression occurs irrespective of SIRT1 activity [22]. Similarly, although resveralogues 1-6 display very similar effects on splicing factor expression, ability to supress the SASP varies widely (as shown in Fig. 2). Indeed, treatment with compound $\mathbf{2}$ significantly elevates levels of IL-8, one of the canonical cytokines that causes paracrine senescence (alongside IL-6). The only consistent change to cytokine levels that we detect is a reduction in IL-10, which is not growth suppressive.

Resveratrol has been reported to modulate the ERK pathway $[35,36]$. ERK signalling has previously been suggested as a potential regulator of splicing factor expression [37]. Indeed, ETS1, a downstream target of ERK signalling has previously been reported to regulate the expression of TRA2B [37]. ERK inhibition has also been demonstrated to suppress cellular senescence [42] and to influence lifespan in animal models [43]. Our data are consistent with these observations, since alterations to ERK signalling with ERK antagonists was also associated with altered splicing factor expression and senescence phenotypes. ERK agonists were also able to ameliorate the effects of resveratrol on both phenotypes. At present, however, we cannot state definitively that this is the primary mode of induction of these effects, given the context and cell type dependence of ERK signalling, and the existence of crosstalk with other pathways. Interpretation of data are also made more complicated by the observation that even a population of senescent cells derived from a single 'young' culture is actually fairly heterogeneous, consisting of deeply senescent, newly senescent and pre-senescent cells. Within a senescent cell culture, there are also several routes by which those cells may have become senescent. These include replicative senescence, mitochondrial senescence, oncogeneinduced senescence, paracrine senescence and autocrine senescence. At the present time, it is unclear whether all subpopulations respond to resveralogue treatment equivalently, or whether cells that have become senescent via different routes respond equivalently to resveralogues.

There is already considerable interest in the development of drugs that can attenuate senescence for eventual human use. Notable successes have come from overcoming apoptosis in senescence using Bcl-2 inhibitors [44], and by modifying mTORC signalling using rapamycin and other rapalogues or ATP mimetics specific for the mTOR kinase active site [31]. SIRT1 is also a current target for drug design and for nutraceutical interventions and is known also to be activated by resveratrol. We suggest that focusing on SIRT1 activity alone may be misleading and that other pathways activated by resveralogues may be more important in alleviating senescence and improving health outcomes in later life. The renewal of proliferation we observe upon resveralogue treatment obviously raises questions about the potential cancer risk attached to such treatment, should it eventually be employed in a clinical setting. We propose that the renewed proliferation arises from a transient increase in telomerase activity brought about by the induction of specific splicing factor proteins, and that the growth is still regulated. This is in accordance with observations that treatment with resveratrol has been suggested to have a protective effect against cancer in both humans and rodent models [45, 46].

\section{Conclusions}

During the ageing process, both senescent and nonsenescent cells lose a degree of response to cellular stressors. The upstream causes of this are as yet unclear, but may include changes in genes controlling alternative splicing; a major regulator of gene expression which ensures genomic plasticity. Here, we provide evidence that treatment with novel analogues of the stilbene compound resveratrol is associated not only with restoration of splicing factor expression but also with amelioration of multiple cellular senescence phenotypes in senescent human primary fibroblasts. At present, the precise mechanisms behind these observations are unclear, but may involve both the restoration of a more 'youthful' pattern of alternative splicing, and also effects of specific splicing factors on telomere maintenance. We propose therefore that splicing factors, and the upstream drivers of splicing factor expression may prove promising as druggable targets to ameliorate ageing phenotypes and hold promise as anti-degenerative compounds effective in human cells in the future.

\section{Methods}

\section{Synthesis of novel resveralogues}

Resveratrol (Sigma Aldrich, UK; 1) was used to synthesise dihydroresveratrol 2 as reported previously [47]. (E)-N-(4(3,5-Dimethoxystyryl)phenyl) methanesulfonamide $\mathbf{3}$ was 
synthesised from the previously reported nitro-substituted analogue 7 via an $\mathrm{Fe} / \mathrm{NH}_{4} \mathrm{Cl}$ reduction to give amine 8 [26], followed by sulfonylation with methanesulfonyl chloride (Fig. 1b). The corresponding amide 9 was also prepared from 8 , by acylation with acetylchloride. The product 9 was subjected to demethylation $\left(\mathrm{BBr}_{3}, \mathrm{CH}_{2} \mathrm{Cl}_{2}\right)$ to give the target compound (E)-N-(4-(3,5-dihydroxystyryl)phenyl)acetamide 4. (E)-5-(4-(3,5-dimethoxystyryl)phenyl)-1H-tetrazole 5 and the isomeric $2-1 H$-tetrazole analogue 6 were prepared directly via acid-catalysed cycloaddition with azide ion from the 4- and 2-cyanostilbenes [26] (10 and 11 respectively). (Fig. 1b) Details of the synthesis, purification and characterisation of the resveralogues are given in Additional file 8.

\section{Determination of SIRT1 enzyme activation}

SIRT1 enzyme activity was measured by using the SIRT1 Fluorometric drug discovery kit (Cayman Chemicals, Michigan, USA) according to the manufacturer's instructions. This assay is a standard direct fluorescent screening assay for SIRT1 ex-vivo and is essentially a variant of the wellknown "fluor de lys" system. For determination of the relative capacity of each resveralogue to activate the enzyme, $25 \mu \mathrm{M}$ solution of each compound $(n=3)$ was preincubated with the enzyme and co-factors before measurement of activity. Quantification was achieved by measuring output at $\lambda_{\mathrm{ex}}=360 \mathrm{~nm}$ and $\lambda_{\mathrm{em}}=460 \mathrm{~nm}$. Each plate included background measurements and enzyme-only controls. Data are presented as fold change (mean $\pm \mathrm{sd}$ ) in activity normalised to enzyme-only and resveratrol $\mathbf{1}$, such that 0 represents no activation, and 1.0 indicates activation equivalent to that observed with resveratrol $\mathbf{1}$.

\section{Determination of cytotoxicity of resveralogue library} A commercial LDH release assay (Pierce LDH Cytotoxicity Assay Kit) was used to determine cell death. Briefly, MRC5 cells (at population doubling $(\mathrm{PD})=45$ ) were seeded in 24 well plates at $1.3 \times 10^{5}$ cells $/ \mathrm{cm}^{2}$ and allowed to recover from trypsinisation for $24 \mathrm{~h}$ then exposed to each of the resveralogues (3 biological replicates $\times 3$ concentrations; 10, 50 and $100 \mu \mathrm{M}$ ) for a further 24 h. $50 \mu \mathrm{l}$ of media from each well was then mixed with an equal volume of LDH assay reaction mixture and incubated at room temperature in the dark for $30 \mathrm{~min} .50 \mu \mathrm{l}$ of $\mathrm{LDH}$ assay stop solution was added to each well and the absorbance of the solution was measured by spectrophotometry at $490 \mathrm{~nm}$. Complete lysis and vehicle only positive and negative controls were included. Data are presented as mean (+/-standard deviation) $\%$ of the total lysis control.

\section{Culture of human primary fibroblasts (NHDF, MRC-5 and HF043)}

Fibroblast cell strains of three genetic backgrounds and two lineages were used in this study: normal human dermal fibroblasts (NHDF; Heidelburg, Germany), human diploid foetal lung fibroblasts (MRC-5; Coriell Institute for Medical Research) and neonatal foreskin fibroblasts (HF043; Dundee Cell Products, UK). Standard culture conditions were a seeding density of $6 \times 10^{4} \mathrm{cells} / \mathrm{cm}^{2}$ in media (C-23020, Promocell, Heidelburg, Germany) containing $1 \%$ penicillin and streptomycin, and a fibroblastspecific supplement mix consisting of foetal calf serum $(3 \% \mathrm{v} / \mathrm{v})$, recombinant fibroblast growth factor $(1 \mathrm{ng} / \mathrm{ml})$ and recombinant human insulin $(5 \mu \mathrm{g} / \mathrm{ml}$ ) (Promocell, Heidelburg, Germany). For the assays requiring senescent cultures, cells were counted and equal numbers of cells seeded at each passage until the growth of the culture slowed to less than $0.5 \mathrm{PD} /$ week as previously described [2] (this occurred at PD $=64$ (NHDF), 65 (MRC-5) and 64 (HF043). Viable cell numbers were determined at each passage by trypan blue staining. For cultures grown under serum starvation conditions, cells were maintained in DMEM (Sigma Aldrich, Dorset, UK) supplemented with $0.1 \%$ of serum and $1 \%$ penicillin and streptomycin in the absence of fibroblast-specific supplement, for $24 \mathrm{~h}$ prior to treatment.

\section{Quantification of secretion of key cytokines}

NHDF cells from a senescent culture were seeded at $6 \times 10^{4}$ cells $/ \mathrm{cm}^{2}$ in a 6 well plate in serum-free media, and after 10 days were treated with $5 \mu \mathrm{M}$ of each of 1-6 for $24 \mathrm{~h}$. Cell supernatants were then harvested and stored at $-80{ }^{\circ} \mathrm{C}$. Levels of 9 cytokines (GMCSF, IFN $\gamma$, IL1 $\beta$, IL2, IL6, IL8, IL10, IL-12p70, and TNF $\alpha$ ) in cell supernatants from treated and vehicle-only control cells were determined using the K15007B MesoScale Discovery multiplex ELISA immunoassay (MSD, Rockville, USA) in 11 replicates. Proteins were quantified relative to a standard curve using a Sector Imager SI-6000 according to the manufacturer's instructions. Data are presented as mean (+/-SEM).

\section{Expression profiling of splicing factor expression in cultures of senescent cells}

NHDF cells were seeded at $6 \times 10^{4}$ cells $/ \mathrm{cm}^{2}$ in 6 well plates, allowed to grow for 10 days then treated with $5 \mu \mathrm{M}$ of each compound for $24 \mathrm{~h}$ in 3 biological replicates, with vehicle only controls (DMSO). Resveratrol 1 acute treatment was at an initial dose of $5 \mu \mathrm{M}$, followed by culture without further treatment for 4 weeks. For chronic treatment regimes, resveratrol (or DMSO vehicle) was added once every $48 \mathrm{~h}$ during 4 weeks. 20 splicing factor transcripts that associated with age and replicative senescence in our previous work $[1,2]$ were selected a priori for assessment here. (Assay identifiers are available on request). RNA was extracted by using $1 \mathrm{ml}$ of TRI reagent ${ }^{\bullet}$ (Life Technologies, Foster City USA) according to the manufacturer's instructions. Total RNA (100 ng) was reverse transcribed in $20 \mu$ reactions using the Superscript III VILO kit (Life 
Technologies, Foster City, USA). Transcript expression was then quantified in triplicate for each biological replicate using TaqMan Low Density Array (TLDA) on the ABIPrism $7900 \mathrm{HT}$ platform. Cycling conditions were 1 cycle each of $50{ }^{\circ} \mathrm{C}$ for $2 \mathrm{~min}, 94.5^{\circ} \mathrm{C}$ for $10 \mathrm{~min}$ and then $40 \mathrm{cy}$ cles of $97{ }^{\circ} \mathrm{C}$ for $30 \mathrm{~s}$ and $57.9^{\circ} \mathrm{C}$ for $1 \mathrm{~min}$. The reaction mixes included $50 \mu \mathrm{l}$ TaqMan Fast Universal PCR Mastermix (Life Technologies, Foster City, USA), $30 \mu \mathrm{d} \mathrm{H} 2 \mathrm{O}$ and $20 \mu \mathrm{l}$ cDNA template. $100 \mu \mathrm{l}$ reaction mixture was dispensed into the TLDA card chamber and centrifuged twice for $1 \mathrm{~min}$ at $1000 \mathrm{rpm}$ to ensure correct distribution of solution to each well. Transcript expression was assessed by the Comparative $\mathrm{Ct}$ approach, relative to the IDH3B, GUSB and PPIA endogenous control genes, selected on the basis of empirical evidence for stability with age in our earlier microarray data [1] and with cellular senescence in our earlier work [2]. Transcript expression was expressed relative to the level of splicing factor expression in vehicle treated control cells.

\section{Assessment of total gene expression and alternative splicing for senescence-related genes}

To assess gene expression and splicing, NHDF cells were seeded at $6 \times 10^{4}$ cells $/ \mathrm{cm}^{2}$ in 6 well plates and after 10 days were treated with $5 \mu \mathrm{M}$ of each compound for $24 \mathrm{~h}$ in 3 biological replicates. Target transcripts included the known age-related genes CDKN2A, CDKN1A, TP53, $M T O R, C H K 1$ and $C H K 2$. Probes specific to particular isoforms or groups of isoforms were designed to unique regions of the transcripts in question. Assays were validated by standard curve analysis of 7 serial 1:2 dilutions of pooled cDNA and proved robust and sensitive with an average efficiency of -3.4 and an average $r^{2}$ for reproducibility between replicates of 0.87 . PCR reactions contained $2.5 \mu \mathrm{l}$ TaqMan Universal Mastermix (no AMPerase) (Applied Biosystems, Foster City, USA), $0.9 \mu \mathrm{M}$ each primer, $0.25 \mu \mathrm{M}$ probe and $0.5 \mu \mathrm{l} \mathrm{cDNA}$ reverse transcribed as above in a total volume of $5 \mu \mathrm{l}$ in a 384 well plate. PCR conditions were a single cycle of $95^{\circ} \mathrm{C}$ for $10 \mathrm{~min}$ followed by 40 cycles of $95^{\circ} \mathrm{C}$ for $15 \mathrm{~s}$ and $60^{\circ} \mathrm{C}$ for $1 \mathrm{~min}$. We also measured the total expression of the ATR, ATM. RB1, SIRT1 and SIRT2 genes. Probe and primer details are available on request. Each biological replicate was tested in triplicate. Isoform-specific and total expression changes were examined for statistical significance by two way ANOVA analysis using SPSS v.22 (IBM, USA).

\section{Catalytic histochemical determination of SA $\beta$-gal positive fraction}

Senescence marker SA $\beta$-Gal was assayed in triplicate using a commercial kit (Sigma Aldrich, UK); according to manufacturer's instructions, with a minimum of 400 cells assessed per replicate.
qRTPCR measurement of transcripts of senescence associated genes

Molecular markers of senescence (CDKN2A and CD248 transcript levels) were measured by qRTPCR relative to the GUSB and PPIA endogenous control genes, on the ABI Prism 7900HT platform. PCR conditions and analysis were as previously described [2].

\section{Live cell capture microscopy}

For live capture microscopy, cells were seeded at a density of $5 \times 10^{4}$ cells per $35 \mathrm{~mm}$ glass bottomed dish (World Precision Instruments, USA) in $2 \mathrm{ml}$ of media. They were then imaged on a Leica Axiovert inverted environmental microscope with heated chamber $\left(37{ }^{\circ} \mathrm{C}\right)$ and $\mathrm{CO}_{2}$ capabilities. An image was taken every $10 \mathrm{~min}$ over the course of $92 \mathrm{~h}$. A $20 \times$ objective was used with a $30 \mathrm{mS}$ shutter speed and 10\% light intensity from a widefield white light source for each image giving optimal contrast and minimal light exposure. Images were analysed using Leica LAS X software.

\section{Determination of cell proliferation}

Senescent cultures of each strain were seeded at $6 \times 10^{4}$ cells $/ \mathrm{cm}^{2}$ into 6 -well plates and cultured for 10 days then treated with $5 \mu \mathrm{M}$ of each compound for $24 \mathrm{~h}$. Cell counts in three replicates of treated and vehicle-only cultures were carried out manually following trypsinisation and suspension of cells and are presented as mean (+/-SEM).

\section{Immunocytochemical determination of Ki67 positive fraction}

Proliferation index was assessed by using Ki67 staining on NHDF cells. Cells were seeded at $1 \times 10^{4}$ cells/coverslip and after 10 days were treated with $5 \mu \mathrm{M}$ of each compound for $24 \mathrm{~h}$ in 3 biological replicates. Cells were fixed for $10 \mathrm{~min}$ with 4\% PFA and permeabilized with $0.025 \%$ Triton and $10 \%$ serum in PBS for $1 \mathrm{~h}$. Cells were then incubated with a rabbit monoclonal anti-Ki67 antibody (ab16667, Abcam, UK) at 1:200 overnight at $4{ }^{\circ} \mathrm{C}$ followed by FITC-conjugated secondary goat anti-rabbit (1:400) for $1 \mathrm{~h}$, and nuclei were counterstained with DAPI. Coverslips were mounted on slides in DAKO fluorescence mounting medium (S3023; Dako). The proliferation index was determined by counting the percentage of Ki67 positive cells from at least 400 nuclei from each biological replicate at $400 \times$ magnification under a Leica D4000 fluorescence microscope.

\section{Assessment of apoptosis using TUNEL assay}

Terminal DNA breakpoints in situ 3 - hydroxy end labeling (TUNEL) was to quantify levels of apoptosis in NHDF cells. Cells were seeded at $1 \times 10^{4}$ cells $/ \mathrm{cm}^{2}$ in 6 well plates and after 10 days were treated with $5 \mu \mathrm{M}$ of 
each compound for $24 \mathrm{~h}$ in 3 biological replicates. The TUNEL assay was performed with Click-iT ${ }^{\circ}$ TUNEL Alexa Fluor 488 Imaging Assay kit (Thermofisher, UK) following the manufacturer's instructions. Negative and positive (DNase1) controls were also performed. The apoptotic index was determined by counting the percentage of positive cells from at least 400 nuclei from each biological replicate at $400 \times$ magnification.

\section{Assessment of apoptosis by assessment of Caspase 3 and 7 activity}

Caspase-3 and-7 activities were assessed as secondary measures of apoptosis. Cells were seeded (1000 cells per well) in a white-walled 96-well plate and then treated with $5 \mu \mathrm{M}$ of each compound for $24 \mathrm{~h}$ in 11 biological replicates alongside vehicle-only controls. Caspase- 3 and -7 activities in the supernatants were then measured by Caspase-Glo 3/7 assay (Promega, Madison, WI, USA) following the manufacturer's instructions. Luminescence was measured by using a BMG Pherastar FSX.

\section{Moderation of ERK signalling pathway with inhibitors and agonists}

The role of ERK signalling in reversal of senescence was investigated using agonists (ceramide) and inhibitors (trametinib) of the ERK pathway. Cells from a senescent culture were seeded at $6 \times 10^{4}$ cells $/ \mathrm{cm}^{2}$ in a 6 well plate in serum free media, and after 10 days were treated with $1-20 \mu \mathrm{M}$ of the ERK inhibitor trametinib (LC laboratories, Woburn, USA for $24 \mathrm{~h}$ hours, or with the ERK agonist N-Acetyl-Dsphingosine (C2-ceramide; Sigma Aldrich, UK) at $20 \mu \mathrm{M}$ for 24 or $120 \mathrm{~h}$. To examine the role of ERK signalling in resveralogue-induced rescue of senescence, HNDF cells were treated with $20 \mu \mathrm{M}$ of the ERK agonist C2-ceramide as above, but with the addition of $5 \mu \mathrm{M}$ resveralogue for $24 \mathrm{~h}$.

Assessment of telomere length in resveratrol treated cells DNA was extracted from $2 \times 10^{5}$ NHDF cells treated with $5 \mu \mathrm{M}$ resveralogue for $24 \mathrm{~h}$, using the PureLink ${ }^{\odot}$ Genomic DNA Mini Kit (Invitrogen ${ }^{\mathrm{Tm}} /$ Thermo Fisher, MA, USA) according to the manufacturer's instructions. DNA quality and concentration was checked by Nanodrop spectrophotometry (NanoDrop/Thermo Fisher, MA, USA). Relative telomere length was assessed by a modified qPCR protocol [48]. PCR reactions contained $1 \mu \mathrm{l}$ EvaGreen (Solis Biodyne, Tartu, Estonia), $2 \mu \mathrm{M}$ each primer and $25 \mathrm{ng}$ DNA in a total volume of $5 \mu \mathrm{l}$ in a 384 well plate. PCR conditions were a single cycle of $95{ }^{\circ} \mathrm{C}$ for 15 min followed by 45 cycles of $95^{\circ} \mathrm{C}$ for $10 \mathrm{~s}$, $60{ }^{\circ} \mathrm{C}$ for $30 \mathrm{~s}$ and $72{ }^{\circ} \mathrm{C}$ for $1 \mathrm{~min}$. Telomere length was calculated using the comparative $\mathrm{Ct}$ approach relative to the $36 B 4$ housekeeping gene and normalised to the quantification from untreated cells. Three biological replicates were tested and each was assessed in triplicate.

\section{Statistical analysis}

Unless otherwise indicated, differences between treated and vehicle-only control cultures were assessed for statistical significance by two way ANOVA analysis using SPSS v.22 (IBM, USA).

\section{Additional files}

\begin{abstract}
Additional file 1: Table S1. Changes in inflammatory proteins following
\end{abstract} treatment with resveratrol analogues. (DOCX 13 kb)

Additional file 2: Table S2. Splicing factor expression and changes in alternative splicing following treatment with resveratrol analogues. (DOCX 19 kb)

Additional file 3: Figure S1. Changes in biochemical and molecular markers of cellular senescence following chronic or repeated treatment with resveratrol. (TIFF 154 kb)

Additional file 4: Figure S2. Live cell capture image following resveratrol treatment. (TIFF $243 \mathrm{~kb}$ )

Additional file 5: Figure S3. Level of necrosis and apoptosis following treatment with resveratrol analogues. (TIFF $230 \mathrm{~kb}$ )

Additional file 6: Figure S4. The effect of manipulation of the ERK pathway with chemical inhibitors and agonists on cellular senescence. (TIFF 193 kb)

Additional file 7: Figure S5. The effect of ERK inhibition on splicing factor expression. (TIFF $143 \mathrm{~kb}$ )

Additional file 8: Synthesis and characterisation of resveralogues. (PDF 3019 kb)

\section{Abbreviations}

DHRSV: Dihydroresveratrol; ESE: Exon splicing enhancer; ESS: Exon splicing silencer; HF043: Neonatal foreskin fibroblast; hnRNP: heterogeneous ribonucleoprotein; ISE: Intron splicing enhancer; ISS: Intron splicing silencer; LDH: Lactate dehydrogenase; MRC5: Human diploid foetal lung; NHDF: Normal human dermal fibroblast; RSV: Resveratrol; SA $\beta$-Gal: Senescence-associated $\beta$ galactosidase; SASP: Senescence associated secretory phenotype; SR: Serine arginine class; TLDA: TaqMan low density array

\section{Acknowledgements}

The authors would like to thank Nicola Jeffery and Ben Lee for technical assistance, and Luke Pilling for help in preparing the heat maps.

\section{Funding}

This work was supported by The Dunhill Medical Trust [grant number: R386/ 1114] to Lorna Harries, a studentship to Vishal Birar from the University of Brighton and Glenn Foundation for Medical Research personal Awards to Richard Faragher and Lynne Cox. Work in Lynne Cox's lab is also supported by BBSRC grant [BB/M006727/1].

Availability of data and materials

All data generated or analysed during this study are included in this published article and its additional information files.

\section{Authors' contributions}

EL carried out the majority of the experiments and reviewed the manuscript. VB carried out the synthesis of the novel compounds. AS contributed to the chemical synthesis of the compounds. JCCJ carried out the live cell microscopy experiments. AH provided technical help for the ERK inhibitor and agonist experiments. HRD oversaw and interpreted the apoptosis assays. DM reviewed the manuscript. LSC supplied senescent fibroblasts and interpreted the data. RGAF interpreted the data, contributed to project direction and reviewed the manuscript, EO managed the chemical aspects of the study interpreted the data and reviewed the manuscript. LWH managed the molecular aspects of the study, interpreted the data and wrote the manuscript. All authors read and approved the final manuscript. 


\section{Ethics approval and consent to participate}

Not applicable.

\section{Consent for publication}

Not applicable.

\section{Competing interests}

The authors declare that they have no competing interests.

\section{Publisher's Note}

Springer Nature remains neutral with regard to jurisdictional claims in published maps and institutional affiliations.

\section{Author details}

'Institute of Biomedical and Clinical Sciences, University of Exeter Medical School, University of Exeter, Barrack Road, Exeter, Devon EX2 5DW, UK. ${ }^{2}$ School of Pharmacy and Biomolecular Sciences, University of Brighton, Cockcroft Building, Moulsecoomb, Brighton BN2 4GJ, UK. ${ }^{3}$ Centre for Biomedical Modelling and Analysis, University of Exeter, Exeter, Devon EX2 5DW, UK. ${ }^{4}$ College of Life and Environmental Sciences, University of Exeter, Exeter, Devon EX4 4QD, UK. ${ }^{5}$ Department of Biochemistry, University of Oxford, Oxford OX1 3QU, UK.

\section{Received: 10 July 2017 Accepted: 9 October 2017} Published online: 17 October 2017

\section{References}

1. Harries LW, Hernandez D, Henley W, Wood AR, Holly AC, Bradley-Smith RM, Yaghootkar H, Dutta A, Murray A, Frayling TM, et al. Human aging is characterized by focused changes in gene expression and deregulation of alternative splicing. Aging Cell. 2011;10:868-78.

2. Holly AC, Melzer D, Pilling LC, Fellows AC, Tanaka T, Ferrucci L, Harries LW. Changes in splicing factor expression are associated with advancing age in man. Mech Ageing Dev. 2013;134:356-66.

3. Lee BP, Pilling LC, Emond F, Flurkey K, Harrison DE, Yuan R, Peters LL, Kuschel G, Ferrucci L, Melzer D, Harries LW. Changes in the expression of splicing factor transcripts and variations in alternative splicing are associated with lifespan in mice and humans. Aging Cell. 2016;15:903-13.

4. Heintz C, Doktor TK, Lanjuin A, Escoubas CC, Zhang Y, Weir HJ, Dutta S, SilvaGarcia CG, Bruun GH, Morantte I, et al. Splicing factor 1 modulates dietary restriction and TORC1 pathway longevity in C. Elegans. Nature. 2016;541:102-6.

5. Lee VM, Goedert M, Trojanowski JQ. Neurodegenerative tauopathies. Annu Rev Neurosci. 2001:24:1121-59.

6. Beyer K, Ariza A. Alpha-Synuclein posttranslational modification and alternative splicing as a trigger for neurodegeneration. Mol Neurobiol. 2013;47:509-24.

7. Wojtuszkiewicz A, Assaraf YG, Maas MJ, Kaspers GJ, Jansen G, Cloos J. PremRNA splicing in cancer: the relevance in oncogenesis, treatment and drug resistance. Expert Opin Drug Metab Toxicol. 2015;11:673-89.

8. Stegeman R, Weake VM. Transcriptional signatures of aging. J Mol Biol. 2017; 429:2427-37.

9. Smith CW, Valcarcel J. Alternative pre-mRNA splicing: the logic of combinatorial control. Trends Biochem Sci. 2000;25:381-8.

10. Cartegni L, Chew SL, Krainer AR. Listening to silence and understanding nonsense: exonic mutations that affect splicing. Nat Rev Genet. 2002;3:285-98.

11. Ramanouskaya TV, Grinev W. The determinants of alternative RNA splicing in human cells. Mol Gen Genomics. 2017;

12. Muller-McNicoll M, Botti V, de Jesus Domingues AM, Brandl H, Schwich OD, Steiner MC, Curk T, Poser I, Zarnack K, Neugebauer KM. SR proteins are NXF1 adaptors that link alternative RNA processing to mRNA export. Genes Dev. 2016; 30:553-66.

13. Kang $X$, Chen W, Kim RH, Kang MK, Park NH. Regulation of the hTERT promoter activity by MSH2, the hnRNPs $\mathrm{K}$ and $\mathrm{D}$, and GRHL2 in human oral squamous cell carcinoma cells. Oncogene. 2009;28:565-74.

14. Pont AR, Sadri N, Hsiao SJ, Smith S, Schneider RJ. mRNA decay factor AUF1 maintains normal aging, telomere maintenance, and suppression of senescence by activation of telomerase transcription. Mol Cell. 2012;47:5-15.

15. Sikora E, Bielak-Zmijewska A, Mosieniak G. Cellular senescence in ageing, age-related disease and longevity. Curr Vasc Pharmacol. 2014;12:698-706.

16. Wang $H$, Han L, Zhao G, Shen H, Wang P, Sun Z, Xu C, Su Y, Li G, Tong T, Chen J. hnRNP A1 antagonizes cellular senescence and senescence- associated secretory phenotype via regulation of SIRT1 mRNA stability. Aging Cell. 2016:15:1063-73.

17. Choi HS, Lee HM, Jang YJ, Kim CH, Ryu CJ. Heterogeneous nuclear ribonucleoprotein $\mathrm{A} 2 / \mathrm{B} 1$ regulates the self-renewal and pluripotency of human embryonic stem cells via the control of the G1/S transition. Stem Cells. 2013;31:2647-58.

18. van Deursen JM. The role of senescent cells in ageing. Nature. 2014;509:439-46.

19. Baker DJ, Childs BG, Durik M, Wijers ME, Sieben CJ, Zhong J, Saltness RA, Jeganathan KB, Verzosa GC, Pezeshki A, et al. Naturally occurring p16(Ink4a)positive cells shorten healthy lifespan. Nature. 2016;530:184-9.

20. Burton DG, Giles PJ, Sheerin AN, Smith SK, Lawton JJ, Ostler EL, RhysWilliams W, Kipling D, Faragher RG. Microarray analysis of senescent vascular smooth muscle cells: a link to atherosclerosis and vascular calcification. Exp Gerontol. 2009;44:659-65.

21. Coppe JP, Patil CK, Rodier F, Sun Y, Munoz DP, Goldstein J, Nelson PS, Desprez PY, Campisi J. Senescence-associated secretory phenotypes reveal cell-nonautonomous functions of oncogenic RAS and the p53 tumor suppressor. PLoS Biol. 2008;6:2853-68.

22. Markus MA, Marques FZ, Morris BJ. Resveratrol, by modulating RNA processing factor levels, can influence the alternative splicing of pre-mRNAs. PLoS One. 2011;6:e28926.

23. Fuggetta MP, Bordignon V, Cottarelli A, Macchi B, Frezza C, Cordiali-Fei P, Ensoli F, Ciafre S, Marino-Merlo F, Mastino A, Ravagnan G. Downregulation of proinflammatory cytokines in HTLV-1-infected T cells by Resveratrol. J Exp Clin Cancer Res. 2016:35:118.

24. Sinclair DA, Guarente L. Small-molecule allosteric activators of sirtuins. Annu Rev Pharmacol Toxicol. 2014;54:363-80

25. Fang EF, Kassahun H, Croteau DL, Scheibye-Knudsen M, Marosi K, Lu H, Shamanna RA, Kalyanasundaram S, Bollineni RC, Wilson MA, et al. NAD+ replenishment improves lifespan and Healthspan in ataxia Telangiectasia models via Mitophagy and DNA repair. Cell Metab. 2016;24:566-81.

26. Birar VC, Sheerin AN, Milkovicova J, Faragher RG, Ostler EL. A facile, stereoselective, one-pot synthesis of resveratrol derivatives. Chem Cent J. 2015;9:26.

27. Chung EY, Kim BH, Hong JT, Lee CK, Ahn B, Nam SY, Han SB, Kim Y. Resveratrol down-regulates interferon-gamma-inducible inflammatory genes in macrophages: molecular mechanism via decreased STAT-1 activation. J Nutr Biochem. 2011;22:902-9

28. Aguilo F, Zhou MM, Walsh MJ. Long noncoding RNA, polycomb, and the ghosts haunting INK4b-ARF-INK4a expression. Cancer Res. 2011;71:5365-9.

29. Pabla N, Bhatt K, Dong Z. Checkpoint kinase 1 (Chk1)-short is a splice variant and endogenous inhibitor of Chk1 that regulates cell cycle and DNA damage checkpoints. Proc Natl Acad Sci U S A. 2012;109:197-202.

30. Harrison DE, Strong R, Sharp ZD, Nelson JF, Astle CM, Flurkey K, Nadon NL, Wilkinson JE, Frenkel K, Carter CS, et al. Rapamycin fed late in life extends lifespan in genetically heterogeneous mice. Nature. 2009;460:392-5.

31. Walters HE, Deneka-Hannemann S, Cox LS. Reversal of phenotypes of cellular senescence by pan-mTOR inhibition. Aging (Albany NY). 2016;8:231-44.

32. Panasyuk G, Nemazanyy I, Zhyvoloup A, Filonenko V, Davies D, Robson M, Pedley RB, Waterfield M, Gout I. mTORbeta splicing isoform promotes cell proliferation and tumorigenesis. J Biol Chem. 2009;284:30807-14.

33. Zhou S, Greenberger JS, Epperly MW, Goff JP, Adler C, Leboff MS, Glowacki J. Age-related intrinsic changes in human bone-marrow-derived mesenchyma stem cells and their differentiation to osteoblasts. Aging Cell. 2008;7:335-43.

34. Ford LP, Wright WE, Shay JW. A model for heterogeneous nuclear ribonucleoproteins in telomere and telomerase regulation. Oncogene. 2002;21: 580-3.

35. Chen $\mathrm{H}$, Jin ZL, Xu H. MEK/ERK signaling pathway in apoptosis of SW620 cell line and inhibition effect of resveratrol. Asian Pac J Trop Med. 2016;9: 49-53.

36. Tillu DV, Melemedjian OK, Asiedu MN, Qu N, De Felice M, Dussor G, Price TJ. Resveratrol engages AMPK to attenuate ERK and mTOR signaling in sensory neurons and inhibits incision-induced acute and chronic pain. Mol Pain. 2012;8:5.

37. Kajita K, Kuwano Y, Kitamura N, Satake Y, Nishida K, Kurokawa K, Akaike Y, Honda M, Masuda K, Rokutan K. Ets1 and heat shock factor 1 regulate transcription of the transformer 2beta gene in human colon cancer cells. J Gastroenterol. 2013;48:1222-33.

38. Kerins JA, Hanazawa M, Dorsett M, Schedl T. PRP-17 and the pre-mRNA splicing pathway are preferentially required for the proliferation versus meiotic development decision and germline sex determination in Caenorhabditis Elegans. Dev Dyn. 2010;239:1555-72. 
39. Anczukow O, Rosenberg AZ, Akerman M, Das S, Zhan L, Karni R, Muthuswamy SK, Krainer AR. The splicing factor SRSF1 regulates apoptosis and proliferation to promote mammary epithelial cell transformation. Nat Struct Mol Biol. 2012;19:220-8.

40. He Y, Brown MA, Rothnagel JA, Saunders NA, Smith R. Roles of heterogeneous nuclear ribonucleoproteins a and B in cell proliferation. J Cell Sci. 2005;118:3173-83.

41. Davis T, Singhrao SK, Wyllie FS, Haughton MF, Smith PJ, Wiltshire M, WynfordThomas D, Jones CJ, Faragher RG, Kipling D. Telomere-based proliferative lifespan barriers in Werner-syndrome fibroblasts involve both p53-dependent and p53-independent mechanisms. J Cell Sci. 2003;116:1349-57.

42. Blagosklonny MV. Aging-suppressants: cellular senescence (hyperactivation) and its pharmacologic deceleration. Cell Cycle. 2009;8:1883-7.

43. Slack C, Alic N, Foley A, Cabecinha M, Hoddinott MP, Partridge L. The Ras-ErkETS-signaling pathway is a drug target for longevity. Cell. 2015;162:72-83.

44. Zhu Y, Tchkonia T, Fuhrmann-Stroissnigg H, Dai HM, Ling YY, Stout MB, Pirtskhalava T, Giorgadze N, Johnson KO, Giles CB, et al. Identification of a novel senolytic agent, navitoclax, targeting the BCl-2 family of anti-apoptotic factors. Aging Cell. 2016;15:428-35.

45. Bishayee A. Cancer prevention and treatment with resveratrol: from rodent studies to clinical trials. Cancer Prev Res (Phila). 2009;2:409-18.

46. Shukla Y, Singh R. Resveratrol and cellular mechanisms of cancer prevention. Ann N Y Acad Sci. 2011;1215:1-8.

47. Faragher RG, Burton DG, Majecha P, Fong NS, Davis T, Sheerin A, Ostler EL. Resveratrol, but not dihydroresveratrol, induces premature senescence in primary human fibroblasts. Age (Dordr). 2011;33:555-64.

48. O'Callaghan NJ, Fenech M. A quantitative PCR method for measuring absolute telomere length. Biol Proced Online. 2011;13:3.

49. Miller JN, Miller JC. Statistics and chemometrics for analytical chemistry. 6th ed. Harlow: Pearson Education; 2010.

\section{Submit your next manuscript to BioMed Central and we will help you at every step:}

- We accept pre-submission inquiries

- Our selector tool helps you to find the most relevant journal

- We provide round the clock customer support

- Convenient online submission

- Thorough peer review

- Inclusion in PubMed and all major indexing services

- Maximum visibility for your research

Submit your manuscript at www.biomedcentral.com/submit 